\title{
Slit/Robo signaling regulates Leydig cell steroidogenesis
}

\author{
Emmanuelle Martinot 10 and Derek Boerboom*
}

\begin{abstract}
Background: First identified as a regulator of neuronal axon guidance, Slit/Robo signaling has since been implicated in additional physiologic and pathologic processes, such as angiogenesis, organogenesis and cancer progression. However, its roles in the regulation of testis function have been little explored.

Methods: Immunohistochemistry and RT-qPCR analyses were performed to detect the expression of Slit/Robo signaling effectors in the adult mouse testis. To identify the roles and mechanisms of Slit/Robo signaling in the regulation of steroidogenesis, RT-qPCR, immunoblotting and hormone measurements were carried out using Leydig cells (primary cultures and the MA10 cell line) treated with exogenous SLIT ligands, and testes from Robo 1-null mice.

Results: Slit1, -2 and -3 and Robo 1 and -2 expression was detected in the adult mouse testis, particularly in Leydig cells. In vitro treatment of Leydig cells with exogenous SLIT ligands led to a decrease in the expression of the steroidogenic genes Star, Cyp 11a1, and Cyp 17a1. SLIT2 treatment decreased the phosphorylation of the key steroidogenic gene regulator CREB, possibly in part by suppressing AKT activity. Furthermore, SLIT2 treatment reduced the responsiveness of MA10 cells to luteinizing hormone by decreasing the expression of Lhcgr. Consistent with these in vitro results, an increase in testicular Star mRNA levels and intra-testicular testosterone concentrations were found in Robo1-null mice. Finally, we showed that the expression of the Slit and Robo genes in Leydig cells is enhanced by testosterone treatment in vitro, by an AR-independent mechanism.
\end{abstract}

Conclusion: Taken together, these results suggest that Slit/Robo signaling represents a novel mechanism that regulates Leydig cell steroidogenesis. It may act in an autocrine/paracrine manner to mediate negative feedback by testosterone on its own synthesis.

Keywords: Slit, Robo, Leydig cell, Steroidogenesis, CREB, AKT, LH responsiveness

\section{Background}

The testis has two main functions: the production of spermatozoa and the synthesis of steroid hormones, mainly androgens. The latter are responsible for the masculinization of the genital tract during fetal development, the development of secondary sexual characteristics at puberty, and the initiation and maintenance of spermatogenesis during adulthood $[1,2]$. Testicular

*Correspondence: derek.boerboom@umontreal.ca

Département de Biomédecine Vétérinaire, Centre de Recherche en Reproduction Et Fertilité, Faculté de Médecine Vétérinaire, Université de Montréal, Saint-Hyacinthe, QC, Canada steroidogenesis is ensured by the Leydig cells, and is mainly under the control of luteinizing hormone (LH) secreted by pituitary gonadotrope cells in response to gonadotropin-releasing hormone $(\mathrm{GnRH})$. $\mathrm{LH}$ interacts with its membrane receptor, LHCGR, to activate Protein Kinase A (PKA) via the production of cAMP by adenylate cyclase [3]. Once activated, PKA phosphorylates the transcription factor cAMP-response element binding protein (CREB) on Ser133, promoting the recruitment of co-activators and the transcription of steroidogenic genes [4]. Besides PKA, CREB can also be phosphorylated at Ser133 by other receptor-activated protein kinases such as calmodulin-dependent protein kinase original author(s) and the source, provide a link to the Creative Commons licence, and indicate if changes were made. The images or other third party material in this article are included in the article's Creative Commons licence, unless indicated otherwise in a credit line to the material. If material is not included in the article's Creative Commons licence and your intended use is not permitted by statutory regulation or exceeds the permitted use, you will need to obtain permission directly from the copyright holder. To view a copy of this licence, visit http://creativecommons.org/licenses/by/4.0/. The Creative Commons Public Domain Dedication waiver (http://creativeco mmons.org/publicdomain/zero/1.0/) applies to the data made available in this article, unless otherwise stated in a credit line to the data. 
(CaMK), mitogen-activated protein kinases (MAPK), and thymoma viral proto-oncogene (AKT) [5-7]. Beyond $\mathrm{LH}$, testosterone itself can regulate its own synthesis, on the one hand via negative feedback on the synthesis and secretion of LH, and on the other hand by acting on Leydig cells in an autocrine/paracrine manner [8-10].

SLIT ligands are secreted glycoproteins which bind cognate single-pass transmembrane receptors of the roundabout (ROBO) family [11, 12]. In vertebrates, 3 SLIT (1-3) and 4 ROBO genes (1-4) have been characterized $[13,14]$. Whereas ROBO1 and ROBO2 are structurally and functionally similar, mammalian $\mathrm{ROBO} 3$ is structurally distinct and lacks the ability to bind SLIT ligands [15]. ROBO4, which is primarily expressed in vascular endothelial cells, encodes an even more highly divergent receptor with shorter extracellular and cytoplasmic regions, and its capacity to directly interact with SLIT ligands is still debated $[15,16]$. First identified as important regulators of axon guidance during nervous system development [17], Slit/Robo family members have since been found to be involved in the regulation of cell adhesion, proliferation and survival in a wide variety of tissues, thereby participating in angiogenesis, organogenesis and tumor progression $[18,19]$. As ROBO receptors lack any enzymatic or autocatalytic activity, SLIT/ROBO complexes mediate their functions via the recruitment of cytoplasmic signaling and scaffolding molecules, including several kinases and regulatory molecules that modify actin and the microtubule cytoskeleton. Notably, ROBO receptors can interact with Slit/Robo GTPase activating proteins (srGAPs) which regulate the activity of Rho GTPases (Cdc42, RhoA, Rac), which in turn alter cell polarity and mobility by modulating the cytoskeleton in neurons and other cell types [20]. Furthermore, Slit and Robo are considered tumor suppressor genes, as they are frequently inactivated in various tumors. For instance, in breast and lung cancer cells, Slit2 expression is frequently lost, and overexpression of Slit2 was associated with an increase in cell adhesion and a decrease in cell proliferation [21]. In this context, SLIT2 appears to signal via AKT/GSK3 $\beta$, thereby modulating the stability and the transcriptional regulatory activity of the proto-oncogene CTNNB1 ( $\beta$-catenin) [22, 23].

Slit/Robo signaling also appears to have important functions in gonadal physiology. In the ovary, Slit/Robo family members are expressed in human and mouse corpora lutea, and blocking Slit/Robo signaling leads to a significant decrease in apoptosis in cultured luteal cells $[24,25]$. Female mice heterozygous-null for both Robo1 and Robo 2 were found to be hyperfertile, with a decrease in granulosa cell apoptosis and follicle atresia [26]. Furthermore, manipulating Slit2 expression in granulosa cells from hen prehierarchical follicles was found to alter
Star and Cyp11a1 mRNA expression, suggesting that Slit/Robo signaling could also modulate ovarian steroidogenesis [27]. In contrast with the ovary, very little is known about Slit/Robo signaling in the testes. Only two studies to date in drosophila showed that /Robo pathway participates in gonad formation, by contributing to somatic gonadal precursor cluster formation and gonad compaction, as well as by controling the ability of somatic cyst stem cells to compete for occupancy in the testis niche $[28,29]$.

In the present study, we sought to determine the potential role(s) of Slit/Robo signaling in the mammalian testis. We determined that Slit/Robo signaling, potentially via $\mathrm{AKT}$, is a potent inhibitor of Leydig cell steroidogenesis. As the expression of the SLIT ligands was found to be upregulated by testosterone, Slit/Robo may therefore represent a novel mechanism whereby testosterone regulates its own biosynthesis.

\section{Methods \\ Animals}

C57Bl/6J mice for Leydig cell primary culture were obtained from the Jackson Laboratory (Bar Harbor, ME). Robo1-null mice were obtained from Dr Alain Chédotal (Sorbonne Université, INSERM, CNRS, Institut de la Vision, Paris, France), and genotype analyses were done as previously described [30]. Animals were housed in temperature-controlled rooms with 14/10 h light/dark cycles, and had ad libitum access to food and water. All animal procedures were approved by the Institutional Animal Care and Use Committee and conformed to the International Guiding Principles for Biomedical Research Involving Animals.

\section{In vivo experiment}

Two to four month-old wild type mice received an i.p. injection of vehicle (sesame oil) or $1 \mathrm{mg}$ of testosterone (MilliporeSigma, Oakville, ON, Canada) $24 \mathrm{~h}$ prior to euthanasia.

\section{MA10 and MLTC1 cell culture}

MA10 and MLTC1 cells were cultured in DMEM/F-12 medium (Thermo Fisher Scientific, Waltham, MA, USA) supplemented with Penicillin/Streptomycin (Wisent, Saint-Jean-Baptiste, QC, Canada) and 15\% horse serum (Thermo Fisher Scientific), and in DMEM medium (Thermo Fisher Scientific) supplemented with $10 \mathrm{mM}$ Hepes (BioShop, Burlington, ON, Canada), $40 \mathrm{mM}$ $\mathrm{NaHCO} 3$ (BioShop), Penicillin/Streptomycin and 10\% fetal bovine serum (MilliporeSigma), respectively, at $37{ }^{\circ} \mathrm{C}$ in an atmosphere containing $5 \% \mathrm{CO}_{2}$. Cells were seeded respectively at $75 \times 10^{3}$ or $60 \times 10^{3}$ cells per well in 48 -well plates. The next day, the culture medium was 
replaced with a serum-free medium, and the cells incubated overnight before treatment with vehicle (PBS) or SLIT recombinant mouse protein (R\&D Systems, Minneapolis, MN, USA, SLIT1 \#5199-SL, SLIT2 \#5444-SL, SLIT3 \#9295-SL) at varying concentrations and for varying times. In some experiments, cells were then treated with human Luteinizing Hormone $(50 \mathrm{ng} / \mathrm{mL}$, National Hormone and Peptide Program, Los Angeles Biomedical Research Institute, Los Angeles, CA, USA), Forskolin (10 $\mu \mathrm{M}$, Selleckchem, Burlington, ON, Canada), or the corresponding vehicle (PBS and DMSO, respectively) for $4 \mathrm{~h}$. Alternatively, cells were treated with vehicle (DMSO), wortmannin (100 nM, TOCRIS, Oakville, ON, Canada), or SC79 $(20 \mu \mathrm{g} / \mathrm{ml}$, MilliporeSigma) for $1 \mathrm{~h}$ and $4 \mathrm{~h}$. Cells were also treated with vehicle (ethanol), or $5 \alpha$-dihydro-11-keto testosterone $(1 \mathrm{nM}, 2 \mathrm{~h}$, Cayman Chemical, Ann Arbor, MI, USA) with or without a pretreatment with flutamide (20 $\mu \mathrm{M}, 1 \mathrm{~h}$, MilliporeSigma).

\section{Leydig cell primary culture}

Leydig cells were isolated from testes of 2- to 4 monthold mice. Testes were decapsulated and digested for 20-30 min at $33^{\circ} \mathrm{C}$ in culture medium (DMEM/F-12 with transferrin $(5 \mu \mathrm{g} / \mathrm{mL}$, MilliporeSigma), insulin $(5 \mu \mathrm{g} / \mathrm{mL}$, MilliporeSigma) vitamin E $(0.2 \mu \mathrm{g} / \mathrm{mL}$, MilliporeSigma), EGF (10 ng/mL, MilliporeSigma), glutamine $(2.5 \mathrm{mM}$, Wisent), Penicillin/Streptomycin and 0.1\% Fetal Bovine Serum) supplemented with $0.2 \mathrm{mg} / \mathrm{mL}$ collagenase (MilliporeSigma), $10 \mu \mathrm{g} / \mathrm{mL}$ DNase I (Roche, Laval, QC, Canada) and 2\% Fetal Bovine Serum. Cells were then pelleted by centrifugation $\left(10 \mathrm{~min}\right.$ at $200 \mathrm{~g}$ and $\left.4{ }^{\circ} \mathrm{C}\right)$ and resuspended in fresh culture medium. After two sedimentation steps, the supernatant containing Leydig cells was centrifuged $\left(10 \mathrm{~min}\right.$ at $200 \mathrm{~g}$ and $\left.4{ }^{\circ} \mathrm{C}\right)$, and the pellet was resuspended in fresh culture medium at a final concentration of $20-30 \times 10^{6}$ cells per mL. $5 \mathrm{~mL}$ of this suspension was deposited on top of a discontinuous Percoll gradient (four layers from 21 to $60 \%$ ) prepared from a 90\% Percoll stock solution (Percoll (GE Healthcare Life Sciences, Marlborough, MA, USA), Ham's F10 (10X, MilliporeSigma), $20 \mathrm{mM}$ Hepes, $140 \mathrm{mM} \mathrm{NaHCO}$, $\mathrm{pH}$ 7.4) diluted with DMEM/F12 culture medium. Purified Leydig cells were collected at the interface between the $60 \%$ and $34 \%$ layers after centrifugation $(30 \mathrm{~min}$ at $500 \mathrm{~g}$ and $4{ }^{\circ} \mathrm{C}$ ), and resuspended in fresh culture medium. Cells were seeded at $45 \times 10^{4}$ cells per well in culture medium in fetal bovine serum-pretreated 48-well plates. The next day, cells were serum starved overnight before treatment with vehicle (PBS) or SLIT2 recombinant mouse protein $(10 \mu \mathrm{g} / \mathrm{mL}$ for $8 \mathrm{~h})$.

\section{Real-time RT-qPCR}

Total RNA from whole testis or Leydig cells (MA10 and MLTC1 cell lines or primary culture) was extracted using the RNeasy Mini Kit (Qiagen, Montreal, QC, Canada) according to the manufacturer's instructions. cDNA was synthesized from 200 ng of RNA using the SuperScript VILO cDNA Synthesis Kit (Thermo Fisher Scientific, Waltham, MA, USA). Real-time PCR reactions were run on a CFX96 Touch Real-Time PCR Detection System (Bio-Rad) using Supergreen Advanced qPCR MasterMix (Wisent). Each PCR reaction consisted of $7.5 \mu \mathrm{L}$ of Supergreen Advanced qPCR MasterMix, $2.3 \mu \mathrm{L}$ of water, $4 \mu \mathrm{L}$ of cDNA sample and $0.6 \mu \mathrm{L}(10 \mathrm{pmol})$ of genespecific primers listed in Table 1. DNA fragment amplification was done using the following thermal cycling program: $3 \mathrm{~min}$ at $95^{\circ} \mathrm{C}$, followed by 40 cycles of $45 \mathrm{~s}$ at $95^{\circ} \mathrm{C}, 30 \mathrm{~s}$ at $60^{\circ} \mathrm{C}$, and $30 \mathrm{~s}$ at $72^{\circ} \mathrm{C}$. Relative mRNA levels were determined with the $\Delta \Delta \mathrm{Ct}$ method using RplpO or $A c t b$ as the housekeeping gene.

Table 1 Quantitative RT-qPCR primer sequences

\begin{tabular}{lll}
\hline Gene & Forward & Reverse \\
\hline Actb & TCATCACTATTGGCAACGAGC & AGTTTCATGGATGCCACAGG \\
Rplpo & AGATTCGGATATGCTGTTGG & AAAGCCTGGAAGAAGGAGGTC \\
Cyplial & GTGACCTTGCAGAGGTACACTGT & GTGACTCCAGCCTTCAGTTCACA \\
Cyp17a1 & CCAGGACCCAAGTGTGTTCT & CCTGATACGAAGCACTTCTCG \\
Hsd3b1 & AGCTGCAGACAAAGACCAAGGTGA & GAACACAGGCCTCCAATAGGTTCT \\
Lhcgr & AGATGCACAGTGGCACCTTCCAG & ATGACGTGGCGATGAGCGTCT \\
Slit1 & CTGCTCCCCGATATGAACC & TAGCATGCACTCACACCTGG \\
Slit2 & AACTTGTACTGCGACTGCCA & TCCTCATCACTGCAGACAAACT \\
Slit3 & AGTTGTCTGCCTTCCGACAG & TTTCCATGGAGGGTCAGCAC \\
Star & TGTCAAGGAGATCAAGGTCCTG & CGATAGACCTGGTTGATGAT \\
Robo1 & GCTGGCGACATGGGATCATA & AATGGGGGCTCTTGAACT \\
Robo2 & CTTTGAACGACCCACATTTCTCA & TCTCAGCGTGTAGTCATCTTTGA \\
\hline
\end{tabular}




\section{Immunoblotting}

MA10 cells were lysed in SDS loading buffer. Protein extracts were resolved on $10 \%$ SDS-polyacrylamide gels, and electrophoretically transferred onto ImmobilonP PVDF membranes (MilliporeSigma). Membranes were probed overnight at $4{ }^{\circ} \mathrm{C}$ with primary antibodies (Table 2) diluted in Tris-buffered saline with $0.1 \%$ tween 20 (TBS-T) containing 5\% bovine serum albumin (BSA) (Jackson Laboratory) or 5\% dried milk, or for $1 \mathrm{~h}$ at room temperature with the anti-ACTB antibody diluted in TBS-T with $5 \%$ dried milk. Following incubation with anti-rabbit IgG HRP Conjugate (1:10,000, WB401B, Promega, Madison, WI, USA), signal was generated using Immobilon Western chemiluminescent horseradish peroxidase substrate (MilliporeSigma). Images were captured with the ChemiDoc MP Imaging System (Bio-Rad), and quantified with Image Lab Software v.5.0 (Bio-Rad).

\section{Immunohistochemistry}

Testes and brain cortex were fixed in Bouin's and formaldehyde solution, respectively, embedded in paraffin and sectioned at a thickness of $3 \mu \mathrm{M}$. Immunohistochemistry was done using the VECTASTAIN Elite ABC HRP Kit (Vector Laboratories, Burlingame, CA, USA) according to the manufacturer's instructions. Slides were then stained with the 3,3'-diaminobenzidine peroxidase substrate kit (Vector Laboratories), and counterstained with hematoxylin before mounting. The primary antibodies used are listed in Table 2.

\section{Hormone measurement}

Progesterone (MA10 cell culture medium) and testosterone (Leydig primary cell culture medium and homogenates of testes from 2 and 4 month-old mice)

Table 2 Antibodies

\begin{tabular}{llll}
\hline Antigen & Company & Catalog number & Dilution factor \\
\hline \multicolumn{2}{l}{ Antibodies for Western blot analysis } & \\
ACTB & Santa Cruz & 47,778 & $1: 10,000$ \\
AKT & Cell signaling & 4691 & $1: 1500$ \\
P-AKT (Ser473) & Cell signaling & 4060 & $1: 2000$ \\
CREB & Cell signaling & 9197 & $1: 1000$ \\
P-CREB (Ser133) & Cell signaling & 9198 & $1: 1000$ \\
GAPDH & Cell signaling & 5174 & $1: 10,000$ \\
mTOR & Cell signaling & 2983 & $1: 1000$ \\
P-mTOR (Ser2448) & Cell signaling & 2971 & $1: 1000$ \\
Antibodies for imm & Anohistochemistry & \\
ROBO1 & Abcam & 7279 & $1: 200$ \\
SLIT1 & Abcam & 129,345 & $1: 200$ \\
SLIT2 & Santa Cruz & 514,499 & $1: 50$ \\
SLIT3 & R\&D Systems & MAB3629 & $1: 100$ \\
\hline
\end{tabular}

concentrations were determined by ELISA. Serum LH levels were measured by radioimmunoassay. All assays were performed by the Ligand Assay and Analysis Core at the University of Virginia (Charlottesville, VA, USA).

\section{Statistical analyses}

The number of samples per group or replicates per experiment is detailed in the corresponding figure legend. Data are presented as means \pm sem. Statistical significance was determined using Student's $t$-test, with $P \leq 0.05$ considered significant.

\section{Results}

Slit and Robo genes are expressed in the Leydig cells of the mouse testis

We first determined which Slit ligands and Robo receptors are expressed in the adult mouse testis by RT-qPCR, using a brain sample as a positive control. Transcripts from all three Slit genes and the canonical receptors Robo1 and Robo2 were detected, although Robo2 was expressed at very low level (Fig. 1a). We then used immunohistochemistry to examine the location of Slit/Robo expression within the testis. ROBO1, SLIT1, -2 and -3 were all found to be strongly expressed, specifically in the interstitial compartment (Fig. 1b), with low levels of SLIT1 and ROBO1 also detectable within the seminiferous tubules. The specificity of the staining was validated using negative (no primary antibody) and positive (brain cortex) controls (Additional file 1: Fig. S1). These results were confirmed at the mRNA level, as all aforementioned Slit/Robo family members were detected in a Leydig cell-enriched sample (Fig. 1a). Although mRNA levels of Robo 1 and -2 and Slit2 and -3 were higher in Leydig cells compared to the whole testis, the opposite was observed for Slit1. Together with the immunohistochemistry analysis, this suggests that Slit 2 and -3 are predominantly expressed in Leydig cells, whereas Slit1 may be predominantly expressed in other testicular cell types.

\section{Exogenous SLIT ligands decrease steroidogenesis in Leydig cells in vitro}

To determine the role of Slit/Robo signaling in Leydig cells, MA10 cells were treated with graded concentrations of exogenous SLIT2 for $4 \mathrm{~h}$, and the mRNA levels of genes encoding steroidogenic enzymes were measured. The addition of SLIT2 decreased Star and Cyp11a1 mRNA levels in a dose-dependent manner (Fig. 2a). Cyp17a1 expression was also significantly decreased, but only at the 1 and $5 \mu \mathrm{g} / \mathrm{mL}$ concentrations (Fig. 2a). $H s d 3 b 1$ mRNA levels were not altered by SLIT2 treatment (not shown). A time course analysis was then done using SLIT2 at $10 \mu \mathrm{g} / \mathrm{mL}$. A decrease in Star and Cyp11a1 mRNA levels was observed at all time points 


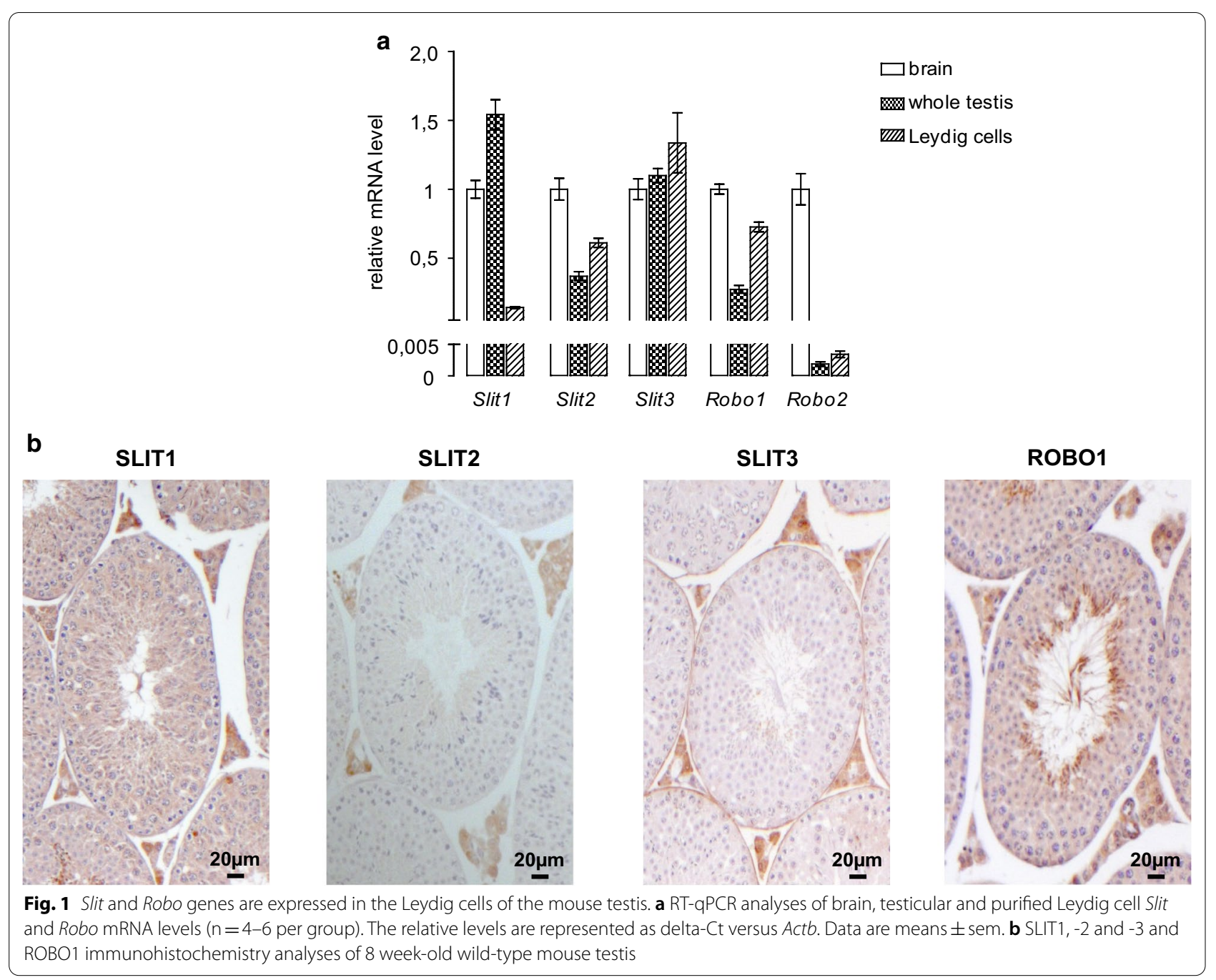

examined, although in both cases this effect had begun to reverse itself after $24 \mathrm{~h}$ of treatment (Fig. 2b). Cyp 17a1 mRNA levels also decreased in response to SLIT2, but more gradually than Star or Cyp11a1, with the decrease becoming statistically significant by 8 h (Fig. 2b). Progesterone concentrations in spent culture medium also appeared lower $8 \mathrm{~h}$ following addition of SLIT2, although the effect was not statistically significant (Fig. 2c). A similar inhibitory effect on steroidogenic gene expression was observed when MA10 cells were treated with exogenous SLIT1, but not with exogenous SLIT3 (Additional file 1: Fig. S2A). However, in another Leydig cell line (MLTC1), all three SLIT recombinant proteins were able to downregulate the expression of the steroidogenic genes (Additional file 1: Fig. S2B), suggesting they may act in a functionally redundant manner. Findings obtained in cell lines were then confirmed in primary cultured Leydig cells. The efficiency of Leydig cell isolation was validated by RT-qPCR using specific Leydig, Sertoli and germ cell markers (Star, Fshr and Dmc1, respectively). As expected, Star was enriched whereas Fshr and Dmc1 were expressed at very low level in the isolated Leydig cells compared to whole testis samples (Additional file 1: Fig. S3). In these cells, we observed a significant decrease of Star and Cyp11a1 mRNA levels in response to SLIT2, with testosterone concentrations trending lower $(P=0.06) 8 \mathrm{~h}$ after treatment (Fig. 2d, e). Together, these results suggest that SLIT ligands can antagonize Leydig cell steroidogenesis by regulating steroidogenic gene expression in a time- and dose-dependent manner.

\section{Exogenous SLIT2 decreases CREB phosphorylation}

CREB is one of the most important transcription factors involved in the regulation of the expression of steroidogenic genes, and is activated by phosphorylation. Interestingly, treating MA10 cells for $1 \mathrm{~h}$ with SLIT2 resulted in a significant decrease in CREB (Ser133) phosphorylation (Fig. 3a). 


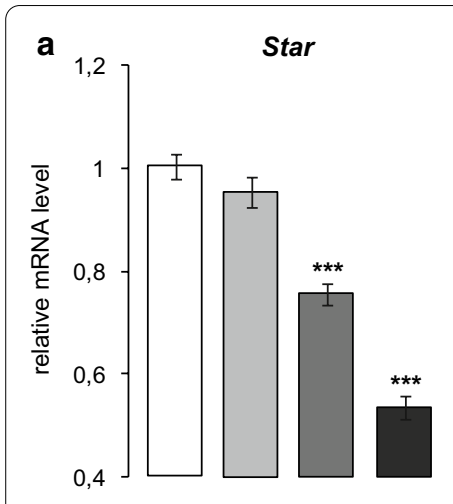

b

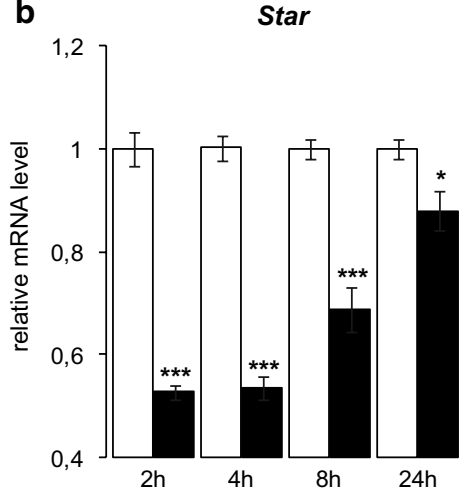

C

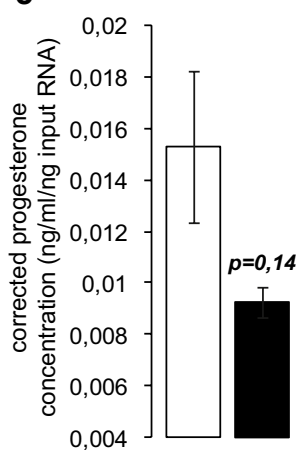

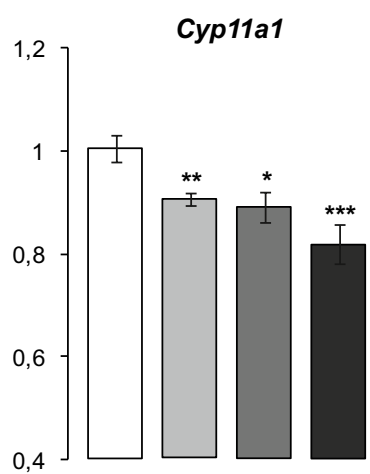

Cyp11a1

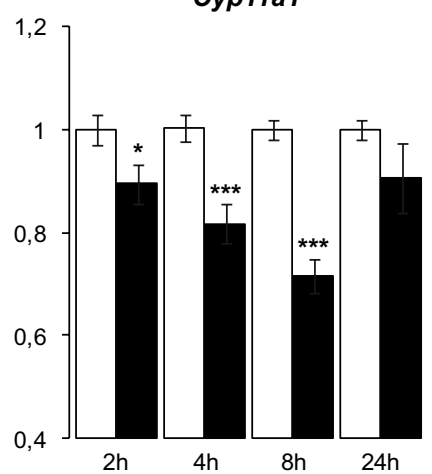

d

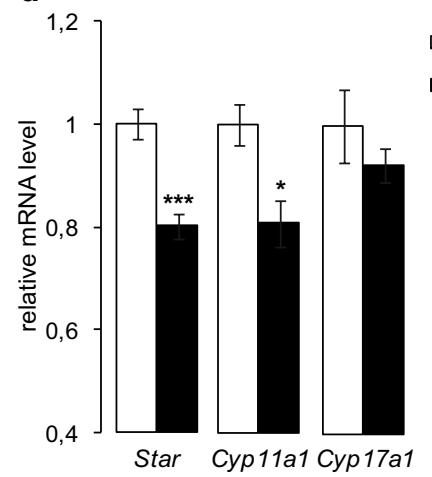

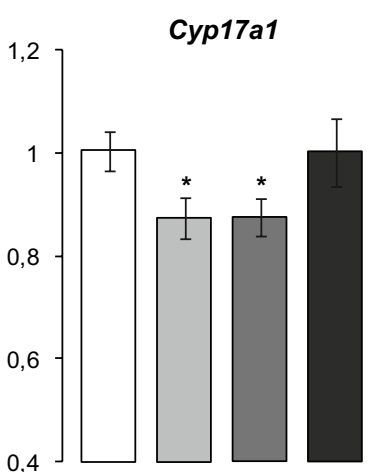

$\square$ PBS

$\square$ SLIT2 $1 \mu \mathrm{g} / \mathrm{ml}$

口SLIT2 $5 \mu \mathrm{g} / \mathrm{ml}$

—SLIT2 $10 \mu \mathrm{g} / \mathrm{ml}$

Cyp17a1

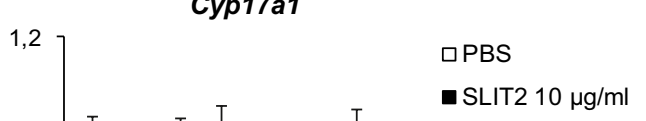

Fig. 2 Exogenous SLIT2 decreases steroidogenesis in Leydig cells in vitro. Expression of Star, Cyp 1 1a1 and Cyp17a1 determined by RT-aPCR in MA10 cells treated $\mathbf{a}$ for $4 \mathrm{~h}$ with vehicle or 1,5 and $10 \mu \mathrm{g} / \mathrm{ml}$ exogenous SLIT2; b for 2, 4, 8 and $24 \mathrm{~h}$ with vehicle or $10 \mu \mathrm{g} / \mathrm{ml}$ SLIT2. c Representative graph of progesterone concentrations (corrected to RNA input) measured in the spent culture media of MA10 cells treated for $8 \mathrm{~h}$ with vehicle or $10 \mu \mathrm{g} / \mathrm{ml} \mathrm{SLIT2.} \mathrm{d} \mathrm{Expression} \mathrm{of} \mathrm{Star,} \mathrm{Cyp} 11$ a 1 and Cyp 17 a 1 determined by RT-qPCR and e representative graph of testosterone concentrations (corrected to RNA input) measured in the spent culture media of mouse primary Leydig cell cultures treated for $8 \mathrm{~h}$ with vehicle or $10 \mu \mathrm{g} / \mathrm{ml} \mathrm{SLIT2}$. Experiments were performed three times in triplicate. Expression of each transcript was normalized to the housekeeping gene Rplp0. Data are means \pm sem; statistical analysis (Student's T-test): ${ }^{*} p<0.05 ;{ }^{* *} p<0.01 ;{ }^{* *} p<0.001$

AKT is a Ser/Thr kinase able to phosphorylate CREB at Ser133 [7]. Importantly, its phosphorylation and activity can be inhibited by Slit/Robo signaling [22], leading us to hypothesize that SLIT2 may suppress steroidogenesis via an AKT-dependent mechanism. We therefore examined the effects of SLIT2 on AKT phosphorylation and activity. AKT phosphorylation decreased significantly in response to SLIT2 (Fig. 3a), and this was correlated with a decrease in phosphorylation of its substrate mTOR (Fig. 3a). Interestingly, the PI3K/AKT inhibitor wortmannin reproduced the decrease in CREB phosphorylation and Star mRNA levels observed in response to SLIT2 (Fig. 3b), whereas the opposite effect was observed with the AKT activator SC79 (Fig. 3c). The efficacy of these 2 drugs was validated as they respectively generated a decrease and an increase in AKT phosphorylation 


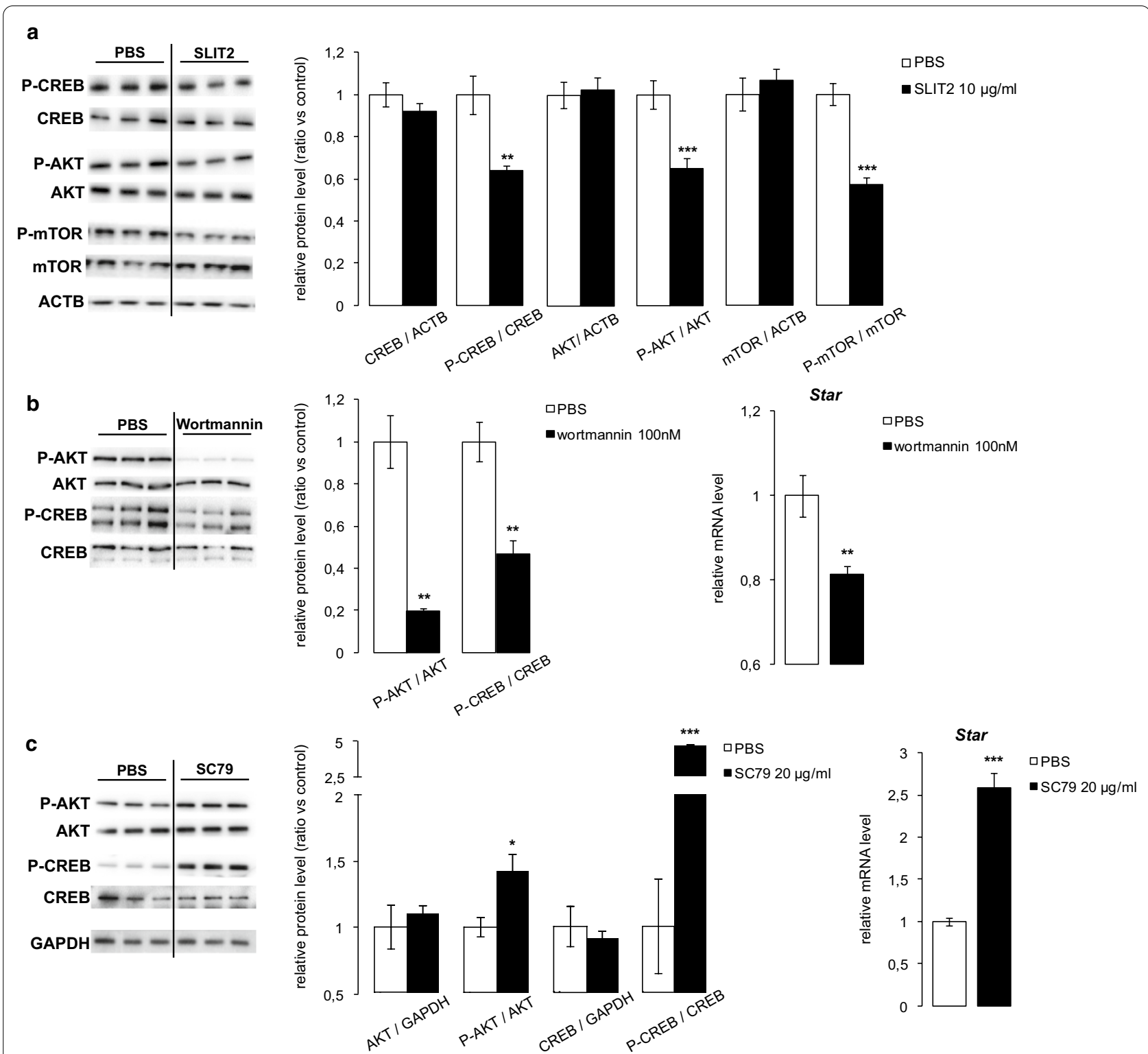

Fig. 3 Exogenous SLIT2 decreases CREB phosphorylation. a Quantification of total and phosphorylated CREB, AKT and mTOR protein levels normalized to ACTB in MA10 cells treated for $1 \mathrm{~h}$ with vehicle or $10 \mu \mathrm{g} / \mathrm{ml} \mathrm{SLIT2.} \mathrm{Quantification} \mathrm{of} \mathrm{total} \mathrm{and} \mathrm{phosphorylated} \mathrm{AKT} \mathrm{and} \mathrm{CREB} \mathrm{protein}$ levels normalized to GAPDH, and expression of Star determined by RT-qPCR, in MA10 cells treated with vehicle or b $100 \mathrm{nM}$ wortmannin, or c $20 \mathrm{\mu g} / \mathrm{ml} \mathrm{SC79}$, for $1 \mathrm{~h}$ (protein) or $4 \mathrm{~h}$ (mRNA). $\mathrm{n}=3-9$ samples per group. Expression of Star was normalized to the housekeeping gene Rplp0. Data are means \pm sem; statistical analysis (Student's $T$-test): ${ }^{*} p<0.05 ;{ }^{* *} p<0.01 ;{ }^{* * *} p<0.001$

(Fig. 3b, c). AKT is therefore able to regulate CREB and Leydig cell steroidogenesis, and its activity can be regulated by Slit/Robo signaling.

\section{Exogenous SLIT2 alters Leydig cell responsiveness to LH by decreasing Lhcgr expression}

A significant, time-dependent decrease in Lhcgr mRNA levels was observed in MA10 cells in response to SLIT2 treatment (Fig. 4a), suggesting that SLIT2 could alter
Leydig cell responsiveness to $\mathrm{LH}$, the most important endocrine regulator of testicular steroidogenesis. To test this, MA10 cells were pre-treated (or not) with exogenous SLIT2 for $24 \mathrm{~h}$ prior to stimulation with LH. The increases in the mRNA levels of the steroidogenic genes Star, Cyp11a1, Cyp17a1 and Hsd3b1 (Fig. 4b) and in CREB phosphorylation (Fig. 4c) in response to $\mathrm{LH}$ were all blunted in cells pre-treated with SLIT2. However, when the experiment was repeated using forskolin (an 

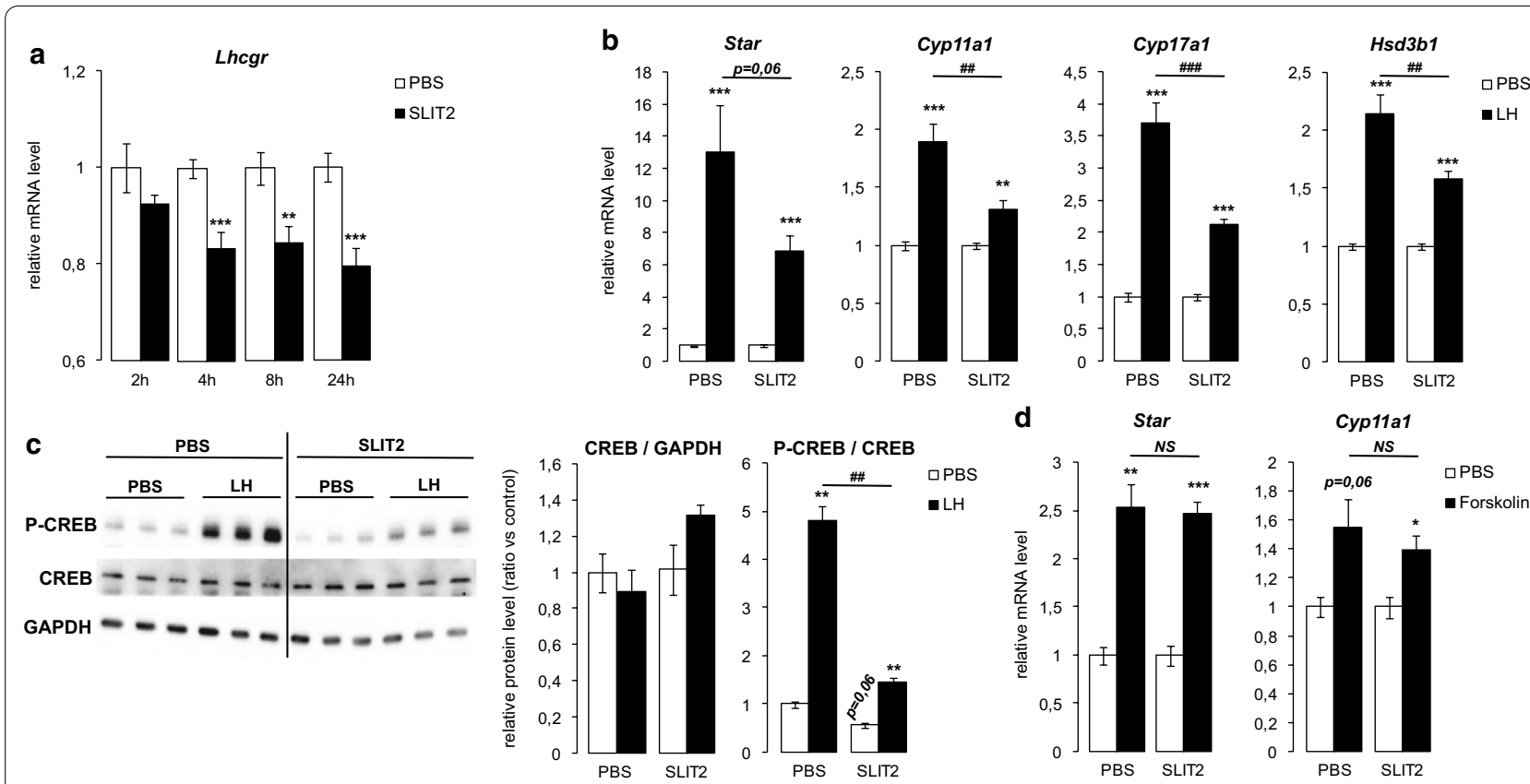

Fig. 4 Exogenous SLIT2 alters Leydig cell responsiveness to LH by decreasing Lhcgr expression. a Expression of Lhcgr determined by RT-qPCR in MA10 cells treated for 2, 4, 8 and $24 \mathrm{~h}$ with vehicle or $10 \mu \mathrm{g} / \mathrm{ml} \mathrm{SLIT2.} \mathrm{b} \mathrm{Expression} \mathrm{of} \mathrm{Star,} \mathrm{Cyp} \mathrm{11a1,} \mathrm{Cyp17a1} \mathrm{and} \mathrm{Hsd3b1} \mathrm{determined} \mathrm{by} \mathrm{RT-qPCR}$ in MA10 cells treated with $10 \mathrm{\mu g} / \mathrm{ml} \mathrm{SLIT2} \mathrm{for} 24 \mathrm{~h}, \pm 50 \mathrm{ng} / \mathrm{ml} \mathrm{LH}$ for $4 \mathrm{~h}$. c Quantification of total and phospho-CREB protein levels normalized to GAPDH in MA10 cells treated with $10 \mu \mathrm{g} / \mathrm{ml} \mathrm{SLIT2} \mathrm{for} 24 \mathrm{~h}, \pm 50 \mathrm{ng} / \mathrm{ml} \mathrm{LH}$ for $30 \mathrm{~min}$. d Expression of Star and Cyp 11 al determined by RT-qPCR in MA10 cells treated with $10 \mu \mathrm{g} / \mathrm{ml}$ SLIT2 for $24 \mathrm{~h}, \pm 10 \mu \mathrm{M}$ forskolin for $4 \mathrm{~h}$. $\mathrm{n}=3-9$ samples per group. Expression of each transcript was normalized to the housekeeping gene Rplp0. Data are means \pm sem; statistical analysis (Student's T-test): ${ }^{*} p<0.05 ;{ }^{* *} p<0.01 ; *^{* *} p<0.001 ; \# p<0.05 ; \# \# p<0.01$; $\# \#$ \# $<0.001$; NS not significant

activator of adenylate cyclase) in lieu of LH, differences in forskolin-stimulated steroidogenic gene mRNA levels between cells pre-treated with vehicle or SLIT2 were not observed (Fig. 4d). The antagonism of LH-stimulated steroidogenic gene expression by SLIT2 therefore seems to be mediated, at least in part, by its suppression of Lhcgr expression.

\section{Increased testicular steroidogenesis in Robo1-null mice}

As Robo1 appeared to be the predominantly expressed canonical SLIT receptor in Leydig cells (Fig. 1), we sought to determine if ROBO1 mediates the inhibitory effect of SLIT2 on steroidogenesis. Leydig cells isolated from wild-type $\left(\right.$ Robol $\left.^{+/+}\right)$and Robo1-null $\left(\right.$Robol $\left.^{-/-}\right)$mice were treated with vehicle or exogenous SLIT2 for $8 \mathrm{~h}$. SLIT2 treatment led to a significant decrease in Star and Cyp11a1 expression in Leydig cells from animals of both genotypes (Fig. 5a), indicating that Robo1 is not essential in this context. RT-qPCR analyses showed 3.5-fold higher Robo 2 mRNA levels in Leydig cells from Robo $1^{-1-}$ mice relative to controls (Fig. 5b), suggesting both the existence of a compensatory mechanism and the functional redundancy of Robo1 and -2 in mediating SLIT2 action in Leydig cells.
Interestingly, Star mRNA levels were significantly higher in untreated primary cultures of Leydig cells from Robo $1^{-1-}$ mice (Fig. 5a), consistent with Star being the gene most responsive to exogenous SLIT ligands in vitro (Fig. 2). These results prompted us to examine testicular steroidogenesis in Robo1 ${ }^{-1-}$ mice. Four month-old Robo $1^{-1-}$ mice were found to have increased testicular Star and Hsd3b1 mRNA levels relative to their wildtype littermates, whereas no difference was observed for Cyp11a1 or Cyp17a1 (Fig. 5c). Lhcgr expression also tended to increase in the mutant animals (Fig. 5c). These results were associated with increased intra-testicular testosterone levels in Robo1 ${ }^{-1-}$ mice at two and four months of age (Fig. 5d). However, no alterations in serum LH levels (Fig. 5d), testis weights, sperm counts, accessory sex organ weights or male fertility were found in Robo1 $^{-/-}$mice (not shown).

\section{The expression of Slit and Robo genes is regulated by testosterone}

Finally, we investigated the physiological context in which Slit/Robo signaling might be activated to inhibit Leydig cell steroidogenesis. As the expression of Slit/Robo genes has been shown to be modulated by steroids $[24,31]$, we 


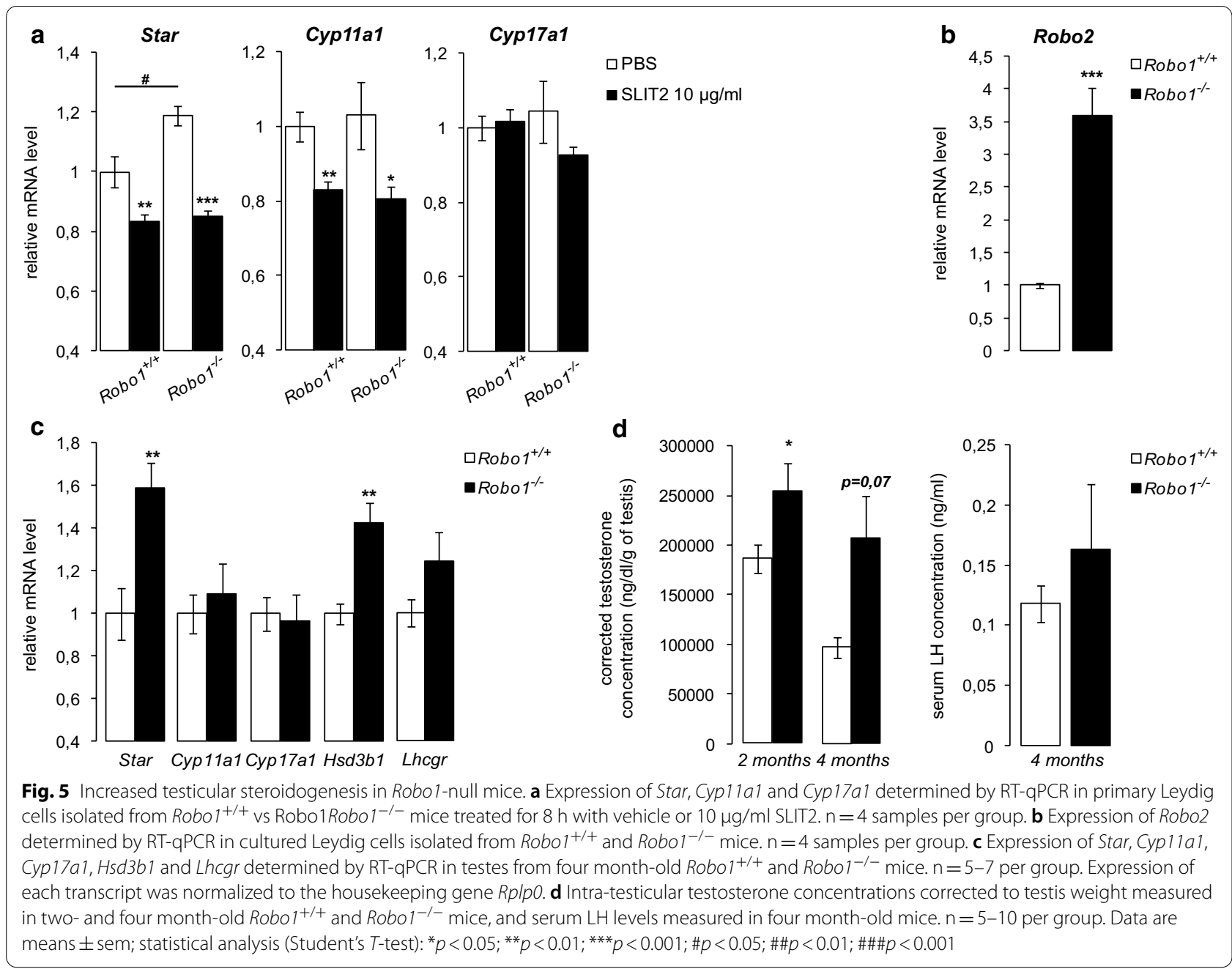

examined the effect of androgens on their mRNA levels in vivo and in vitro. Injection of $1 \mathrm{mg}$ of testosterone in wild-type mice led to an increase in testicular Slit1, $-2,-3$ and Robo1 mRNA levels, which was significant for all these genes except for Slit2 (Fig. 6a). In order to determine if androgens regulate Slit/Robo genes expression more specifically in Leydig cells, MA10 cells were treated with $5 \alpha$-dihydro-11-keto testosterone $(1 \mathrm{nM})$ for $2 \mathrm{~h}$. This caused the mRNA levels of all Slit genes, Robo1 and Robo 2 to either trend higher or increase significantly (Fig. 6b), suggesting an autoregulatory feedback loop on Leydig cell steroidogenesis (Fig. 7). To determine if the androgen receptor (AR) is involved in the regulation of Slit/Robo genes by androgens, the MA10 cell line was pre-treated for $1 \mathrm{~h}$ with the AR inhibitor Flutamide prior to addition of $5 \alpha$-dihydro-11-keto testosterone. $5 \alpha$-dihydro-11-keto testosterone was able to increase the mRNA levels of Slit/Robo genes in absence or in presence of Flutamide (Fig. 6c), suggesting that the mechanism of their regulation by androgens is AR-independent.

\section{Discussion}

Although LH is widely regarded as the major endocrine regulator of testicular steroidogenesis, many studies have now shown that testosterone synthesis by Leydig cells is also modulated by a number of autocrine/paracrine-acting factors. These include growth factors and cytokines such as IGF1, FGF9, TGF $\beta 1$, TNF $\alpha$, AMH, Il1 and Il6 [32]. Importantly, testosterone itself also regulates its own synthesis, as shown by several studies that have employed gene targeting techniques in mice to inactivate the androgen receptor (AR) in Leydig cells $[9,10]$. With this study, we propose that Slit/Robo signaling represents a novel autocrine mechanism that regulates Leydig cell steroidogenesis. The negative effect of SLIT treatment of Leydig cells in vitro on Lhcgr and steroidogenic gene expression, CREB phosphorylation and LH signaling, coupled with increased Leydig cell Star expression and testosterone synthesis in Robo1-null mice, all argue that the physiological role of Slit/Robo signaling in Leydig cells is to antagonize LH-driven steroidogenesis. 


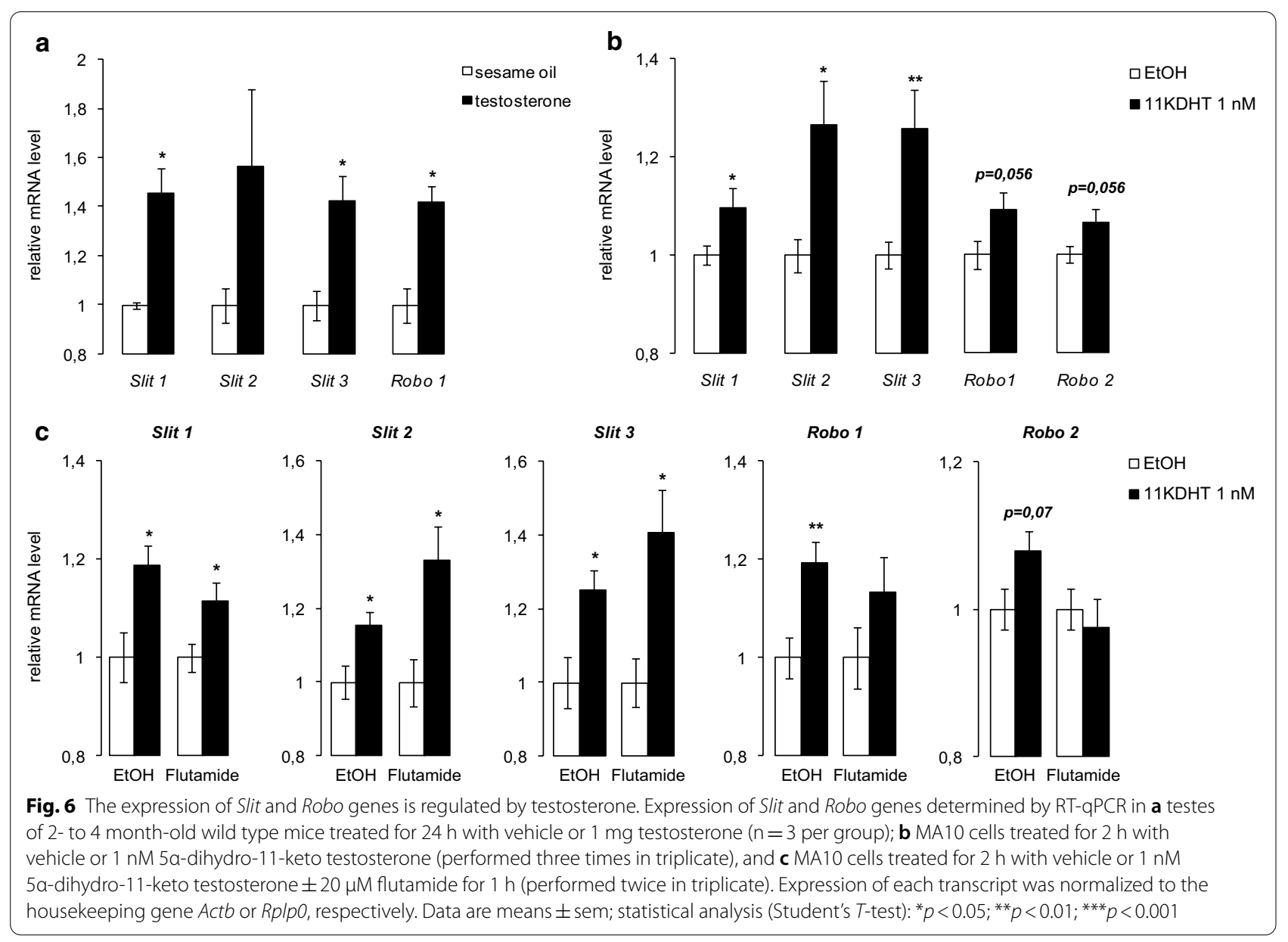

Whereas the ability of testosterone to regulate its own synthesis is well-established, how it does so remains unknown, other than that AR is a key mediator of its action $[9,10]$. Here, we show that testosterone up-regulates the expression of Slit and Robo genes in Leydig cells, creating a potential negative feedback loop that would permit high local testosterone levels to induce Slit/Robo signaling, thereby inhibiting Lhcgr expression and LH signaling, and resulting in decreased testosterone synthesis (Fig. 7). Although further validation of this working model is clearly warranted, this mechanism nonetheless suggests a novel level of local control over steroidogenesis that could fine-tune the endocrine LH signal. In our model, androgens seem to regulate Slit and Robo gene expression in an AR-independent manner. Such ARindependent actions of androgens have been described in several cell types, including macrophages, $\mathrm{T}$ cells and neuroblastoma cells [33-35]. In these cells, testosterone induces a rapid rise in intracellular $\mathrm{Ca}^{2+}$ levels that is not affected by pharmacologic inhibitors of AR. Elevated $\mathrm{Ca}^{2+}$ in turn induces signal transduction cascades and modulation of transcription [36]. How testosterone regulates Slit and Robo gene expression in Leydig cells will be grounds for further study, but a $\mathrm{Ca}^{2+}$ - dependant mechanism could certainly be involved.

Further mechanistic investigation will also be required to better define how Slit/Robo antagonizes LH signaling. In this report, we show that SLIT2 treatment of Leydig cells reduces Lhcgr levels, presumably thereby decreasing their responsiveness to LH. Whether the observed decrease in AKT activity that occurs in response to SLIT2 represents the signaling mechanism that drives the decrease in Lhcgr expression remains to be determined. As CREB is a substrate of both PKA and AKT, another possibility is that Slit/Robo antagonizes LH signaling by decreasing CREB phosphorylation (Fig. 7). Indeed, our data suggest that both basal and LH-induced CREB phosphorylation are decreased by SLIT2 treatment, indicating that some level of AKT activity must be present for optimal CREB phosphorylation and a robust $\mathrm{LH}$ response. The signals that drive AKT activity in Leydig cells in this context will need to be established, but one possibility is LH itself, which signals via AKT in ovarian theca interna cells [37, 38], and may do so in Leydig cells as well [39]. 


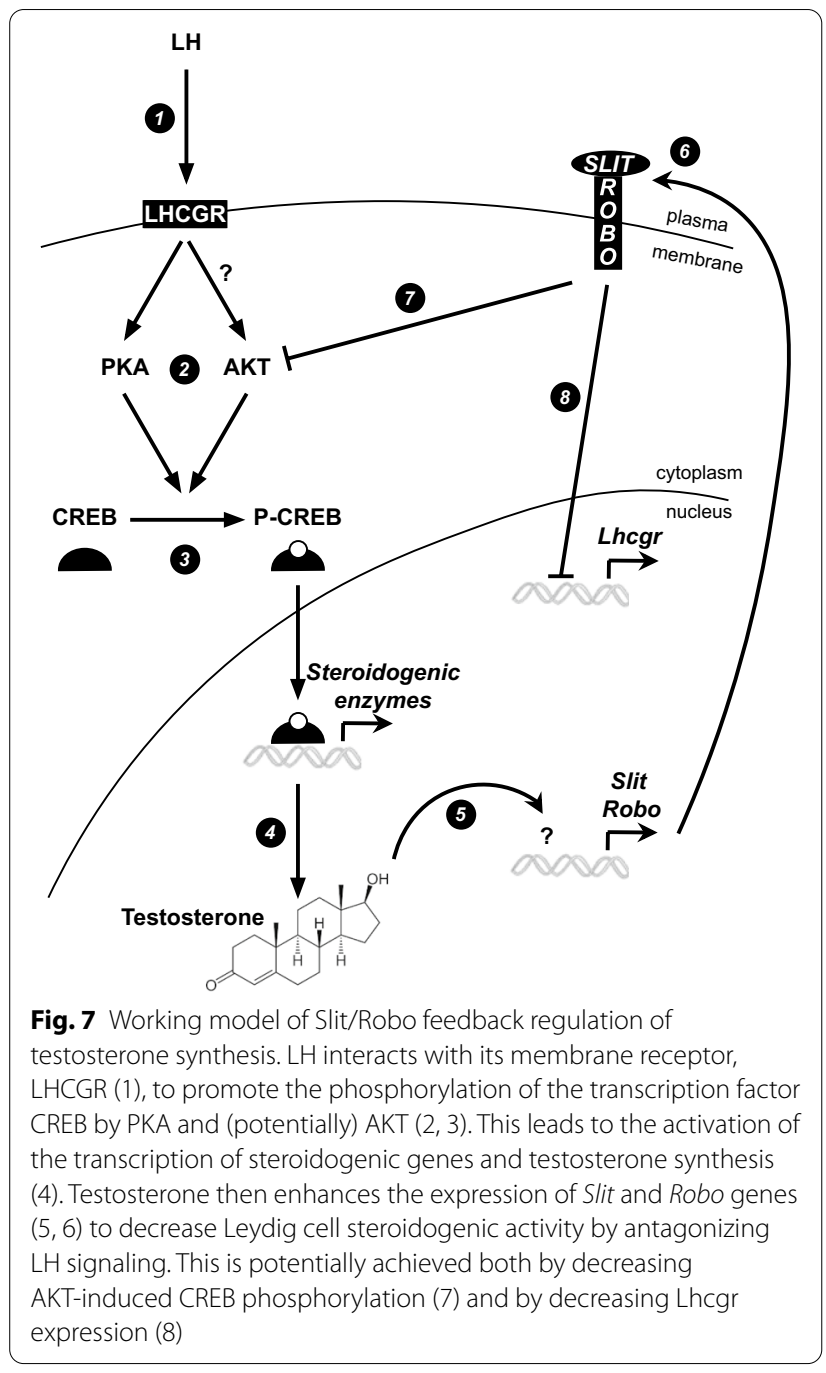

Our descriptive data showed higher expression of Slit2 and -3 and Robo1 in a Leydig cell-enriched sample relative to whole testes, suggesting that they are primarily expressed in this cell type. However, some level of expression (and Slit/Robo signaling activity) in other testicular cell type(s) can't be excluded, and indeed would seem likely. Consistent with this, Slit1 was found to be more expressed in whole testes relative to Leydig cells. As SLITs are secreted proteins, they could thus participate in the regulation of Leydig cell steroidogenesis in both an autocrine and paracrine manner. Conversely, Slit/Robo signaling could also act in other testicular cell types to play roles in the regulation of other functions, such as spermatogenesis, which has not been explored so far in mammals.

A functional redundancy amongst the SLIT ligands and amongst the ROBO receptors has been previously described in the literature [27, 30]. Although SLIT3 appeared less potent than SLIT1 or -2 in the MA10 cell line, all three ligands were similarly effective in MLTC1 cells, also suggesting that functional redundancy occurs in the context of the regulation of Leydig cell steroidogenesis, at least in vitro. To determine which ligand(s) play(s) a preponderant role in the physiologic context will likely require the conditional targeting of all Slit genes, individually and in combination. Likewise, our data showing that SLIT2 is equally effective at suppressing steroidogenic gene expression in Leydig cells from wild-type and $R_{o b o 1^{-1-}}$ mice argue that ROBO1 is not the sole canonical SLIT receptor in this cell type. This was an unexpected outcome given our data showing very low levels of Robo 2 expression in the testis, as $\mathrm{ROBO} 2$ is the receptor most structurally and functionally related to ROBO1 [18], and hence the likeliest to be able to offset its loss. However, an apparent compensatory increase in Robo 2 mRNA levels was observed in Leydig cells from Robo $^{-1-}$ mice, perhaps enough to restore adequate Slit/Robo signaling for SLIT2 to able to exert its effects. Importantly, Star mRNA levels and testosterone synthesis were increased in the testes of $\mathrm{Robol}^{-1-}$ mice, suggesting that $\mathrm{ROBO} 1$ does indeed transduce a steroidogenesis-inhibitory signal in vivo, and that Robo 2 overexpression does not completely compensate for the loss of Robo1.

\section{Conclusions}

In summary, we have identified Slit/Robo as a novel signaling mechanism that regulates Leydig cell steroidogenesis. The induction of Slit and Robo gene expression by testosterone, coupled with the suppressive effect of Slit/ Robo on LH signaling and steroidogenesis, suggest a negative feedback loop that permits testosterone to regulate its own synthesis. Beyond broadening our understanding of the regulation of testicular steroidogenesis, our findings may provide insight into the pathogenesis and/or treatment of disorders of male reproductive tract development, hypogonadism and infertility.

\section{Supplementary information}

The online version contains supplementary material available at https://doi. org/10.1186/s12964-020-00696-6.

Additional file 1. Supplemental Figures.

\section{Abbreviations}

AR: Androgen receptor; CAMK: Calmodulin-dependent protein kinase; CREB: CAMP-response element binding protein; Cyp11a1: Cytochrome P450, family 11, subfamily a, polypeptide 1; Cyp17a1: Cytochrome P450, family 17, subfamily a, polypeptide 1; GnRH: Gonadotropin-Releasing hormone; GTPase: GTP hydrolase; Hsd3b1: Hydroxy-delta-5-steroid dehydrogenase, 3 beta-and steroid delta-isomerase 1; LH: Luteinizing hormone; MAPK: Mitogen-activated protein kinase; PKA: Protein kinase A; srGAP: Slit/Robo GTPase activating proteins; Star: Steroidogenic acute regulatory protein. 


\section{Acknowledgements}

The authors thank Alain Chédotal for generously providing Robo1-null mice. The authors thank the Ligand Assay and Analysis Core at the University of Virginia (Charlottesville, VA, USA) for the hormonal measurements.

\section{Authors' contributions}

$\mathrm{DB}$ and EM co-designed the overall study. EM performed acquisition of data. DB and EM analyzed the data and wrote the manuscript. Both authors revised, read and approved the final manuscript.

\section{Funding}

This work was supported by Canadian Institutes of Health Research (CIHR) operating Grant MOP-142445 (to DB). EM was supported by a post-doctoral research award from the Fonds de Recherche du Québec -Santé (FRQS). The University of Virginia Center for Research in Reproduction Ligand Assay and Analysis Core is supported by U.S. National Institutes of Health, Eunice Kennedy Shriver National Institute of Child Health and Human Development Specialized Cooperative Centers Program in Reproduction Research (SCCPRR) Grant U54-HD28934. The funders were not involved in study design, data collection and analysis, decision to publish, or preparation of the manuscript.

\section{Availability of data and materials}

All data generated or analyzed during this study are included in this published article [and its supplementary information files].

\section{Ethics approval and consent to participate}

All animal procedures were approved by the Institutional Animal Care and Use Committee and conformed to the International Guiding Principles for Biomedical Research Involving Animals.

\section{Consent for publication}

Not applicable.

\section{Competing interests}

The authors declare that they have no competing interests.

Received: 9 June 2020 Accepted: 10 December 2020

Published online: 21 January 2021

\section{References}

1. Wilson JD, Griffin JE, George FW, Leshin M. The endocrine control of male phenotypic development. Aust J Biol Sci. 1983;36(2):101-28.

2. Singh J, O'Neill C, Handelsman DJ. Induction of spermatogenesis by androgens in gonadotropin-deficient (hpg) mice. Endocrinology. 1995;136(12):5311-21.

3. Dufau ML, Watanabe K, Catt KJ. Stimulation of cyclic AMP production by the rat testis during incubation with hCG in vitro. Endocrinology. 1973:92(1):6-11.

4. Manna PR, Dyson MT, Eubank DW, Clark BJ, Lalli E, Sassone-Corsi P, et al. Regulation of steroidogenesis and the steroidogenic acute regulatory protein by a member of the CAMP response-element binding protein family. Mol Endocrinol. 2002;16(1):184-99.

5. Sheng M, Thompson MA, Greenberg ME. CREB: a Ca(2+)-regulated transcription factor phosphorylated by calmodulin-dependent kinases. Science. 1991;252(5011):1427-30.

6. Ginty DD, Bonni A, Greenberg ME. Nerve growth factor activates a Ras-dependent protein kinase that stimulates c-fos transcription via phosphorylation of CREB. Cell. 1994;77(5):713-25.

7. Du K, Montminy M. CREB is a regulatory target for the protein kinase Akt/ PKB. J Biol Chem. 1998;273(49):32377-9.

8. Hileman SM, Lubbers LS, Petersen SL, Kuehl DE, Scott CJ, Jackson GL. Influence of testosterone on LHRH release, LHRH mRNA and proopiomelanocortin mRNA in male sheep. J Neuroendocrinol. 1996;8(2):113-21.

9. Xu Q, Lin H-Y, Yeh S-D, Yu I-C, Wang R-S, Chen Y-T, et al. Infertility with defective spermatogenesis and steroidogenesis in male mice lacking androgen receptor in Leydig cells. Endocrine. 2007;32(1):96-106.

10. O'Hara L, Mclnnes K, Simitsidellis I, Morgan S, Atanassova N, Slowikowska-Hilczer J, et al. Autocrine androgen action is essential for Leydig cell maturation and function, and protects against late-onset Leydig cell apoptosis in both mice and men. FASEB J. 2015;29(3):894-910.

11. Brose K, Bland KS, Wang KH, Arnott D, Henzel W, Goodman CS, et al. Slit proteins bind Robo receptors and have an evolutionarily conserved role in repulsive axon guidance. Cell. 1999;96(6):795-806.

12. Yuan W, Zhou L, Chen JH, Wu JY, Rao Y, Ornitz DM. The mouse SLIT family: secreted ligands for $\mathrm{ROBO}$ expressed in patterns that suggest a role in morphogenesis and axon guidance. Dev Biol. 1999:212(2):290-306.

13. Yuan SS, Cox LA, Dasika GK, Lee EY. Cloning and functional studies of a novel gene aberrantly expressed in RB-deficient embryos. Dev Biol. 1999;207(1):62-75.

14. Huminiecki L, Gorn M, Suchting S, Poulsom R, Bicknell R. Magic roundabout is a new member of the roundabout receptor family that is endothelial specific and expressed at sites of active angiogenesis. Genomics. 2002;79(4):547-52.

15. Zelina P, Blockus H, Zagar Y, Péres A, Friocourt F, Wu Z, et al. Signaling switch of the axon guidance receptor Robo3 during vertebrate evolution. Neuron. 2014;84(6):1258-72.

16. Morlot C, Thielens NM, Ravelli RBG, Hemrika W, Romijn RA, Gros P, et al. Structural insights into the Slit-Robo complex. Proc Natl Acad Sci USA. 2007;104(38):14923-8.

17. Kidd T, Bland KS, Goodman CS. Slit is the midline repellent for the robo receptor in Drosophila. Cell. 1999;96(6):785-94.

18. Blockus H, Chédotal A. Slit-Robo signaling. Development. 2016;143(17):3037-44.

19. Tong M, Jun T, Nie Y, Hao J, Fan D. The role of the slit/robo signaling pathway. J Cancer. 2019;10(12):2694-705.

20. Lucas B, Hardin J. Mind the (sr)GAP- roles of Slit-Robo GAPs in neurons, brains and beyond. J Cell Sci. 2017;130(23):3965-74.

21. Dallol A, Da Silva NF, Viacava P, Minna JD, Bieche I, Maher ER, et al. SLIT2: a human homologue of the Drosophila Slit2 gene, has tumor suppressor activity and is frequently inactivated in lung and breast cancers. Cancer Res. 2002;62(20):5874-80.

22. Prasad A, Paruchuri V, Preet A, Latif F, Ganju RK. Slit-2 induces a tumorsuppressive effect by regulating beta-catenin in breast cancer cells. J Biol Chem. 2008;283(39):26624-33.

23. Tseng R-C, Lee S-H, Hsu H-S, Chen B-H, Tsai W-C, Tzao C, et al. SLIT2 attenuation during lung cancer progression deregulates beta-catenin and E-cadherin and associates with poor prognosis. Cancer Res. 2010;70(2):543-51.

24. Dickinson RE, Myers M, Duncan WC. Novel regulated expression of the SLIT/ROBO pathway in the ovary: possible role during luteolysis in women. Endocrinology. 2008;149(10):5024-34.

25. Zhang X, Li J, Liu J, Luo H, Gou K, Cui S. Prostaglandin F2a upregulates Slit/Robo expression in mouse corpus luteum during luteolysis. J Endocrinol. 2013;218(3):299-310.

26. Li J, Ye Y, Zhang R, Zhang L, Hu X, Han D, et al. Robo1/2 regulate follicle atresia through manipulating granulosa cell apoptosis in mice. Sci Rep. 2015;5:9720.

27. Xu R, Qin N, Xu X, Sun X, Chen X, Zhao J. Inhibitory effect of SLIT2 on granulosa cell proliferation mediated by the CDC42-PAKs-ERK1/2 MAPK pathway in the prehierarchical follicles of the chicken ovary. Sci Rep. 2018;8(1):9168

28. Weyers JJ, Milutinovich AB, Takeda Y, Jemc JC, Van Doren M. A genetic screen for mutations affecting gonad formation in Drosophila reveals a role for the slit/robo pathway. Dev Biol. 2011;353(2):217-28.

29. Stine RR, Greenspan LJ, Ramachandran KV, Matunis EL. Coordinate regulation of stem cell competition by Slit-Robo and JAK-STAT signaling in the Drosophila testis. PLoS Genet. 2014;10(11):e1004713.

30. Long H, Sabatier C, Ma L, Plump A, Yuan W, Ornitz DM, et al. Conserved roles for Slit and Robo proteins in midline commissural axon guidance. Neuron. 2004;42(2):213-23.

31. Zhang X, Mi M, Hao W, Fan Q, Gao B. Progesterone down-regulates SLIT/ROBO expression in mouse corpus luteum. Acta Histochem. 2017;119(7):740-6.

32. Tremblay JJ. Molecular regulation of steroidogenesis in endocrine Leydig cells. Steroids. 2015;103:3-10.

33. Benten WP, Lieberherr M, Stamm O, Wrehlke C, Guo Z, Wunderlich F. Testosterone signaling through internalizable surface receptors in androgen receptor-free macrophages. Mol Biol Cell. 1999;10(10):3113-23. 
34. Benten WP, Lieberherr M, Giese G, Wrehlke C, Stamm O, Sekeris CE, et al. Functional testosterone receptors in plasma membranes of T cells. FASEB J. 1999;13(1):123-33.

35. Estrada M, Uhlen P, Ehrlich BE. Ca2+ oscillations induced by testosterone enhance neurite outgrowth. J Cell Sci. 2006;119(Pt 4):733-43.

36. Mellström B, Naranjo JR. Mechanisms of $\mathrm{Ca}(2+)$-dependent transcription. Curr Opin Neurobiol. 2001;11(3):312-9.

37. Fukuda S, Orisaka M, Tajima K, Hattori K, Kotsuji F. Luteinizing hormoneinduced Akt phosphorylation and androgen production are modulated by MAP Kinase in bovine theca cells. J Ovarian Res. 2009;2:17.

38. Wang X, Zou P, He Y, Meng K, Quan F, Zhang Y. Effect of luteinizing hormone on goat theca cell apoptosis and steroidogenesis through activation of the PI3KJAKT pathway. Anim Reprod Sci. 2018;190:108-18.
39. Tai P, Shiraishi K, Ascoli M. Activation of the lutropin/choriogonadotropin receptor inhibits apoptosis of immature Leydig cells in primary culture. Endocrinology. 2009;150(8):3766-73.

\section{Publisher's Note}

Springer Nature remains neutral with regard to jurisdictional claims in published maps and institutional affiliations.
Ready to submit your research? Choose BMC and benefit from:

- fast, convenient online submission

- thorough peer review by experienced researchers in your field

- rapid publication on acceptance

- support for research data, including large and complex data types

- gold Open Access which fosters wider collaboration and increased citations

- maximum visibility for your research: over $100 \mathrm{M}$ website views per year

At BMC, research is always in progress.

Learn more biomedcentral.com/submissions 